\title{
Severity of Anxiety During COVID-19 Outbreak and Its Relationship with self-related skills of Executive Functions in Children
}

\section{sakineh soltani ( $\nabla$ s.soltani@um.ac.ir)}

Ferdowsi University of Mashhad https://orcid.org/0000-0003-1469-0244

maryam bordbar

Ferdowsi University of Mashhad

Somayeh Zarenejhad

Ferdowsi University of Mashhad

Seyedeh Manizheh arabi

Ferdowsi University of Mashhad

\section{Research article}

Keywords: self-motivation, self-management, self-restraint, self-regulation, self-organization, coronavirus

Posted Date: July 9th, 2020

DOI: https://doi.org/10.21203/rs.3.rs-40680/v1

License: (9) This work is licensed under a Creative Commons Attribution 4.0 International License. Read Full License 


\section{Abstract}

Background: Some children experience a greater deal of anxiety during the outbreak of COVID-19. Behavioral dimensions of executive function appear to be linked to situational anxiety experience. Therefore, the primary aim of the present study is to investigate the relationship between self-related skills of executive functions before the outbreak of COVID-19 and the level of physical and mental anxiety in children during this pandemic. Also, the secondary goal of this study is to predict the level of anxiety based on self-related skills of executive functions.

Methods: Information were obtained from Barkley Deficits in Executive Functioning Scale (BDEFS), which was collected from 300 healthy children over two months before the COVID-19 outbreak. The children anxiety was measured based on parent's reposes to an online anxiety scale when the disease outbreak.

Results: The results showed that the total score of self-related skills of executive functions was negatively and significantly related to the anxiety level $(r=-.53)$. In general, the results also demonstrated that selfrelated skills of executive functions can predict $28 \%$ of anxiety. The subscales of self-management $(p<0.015$, $t=5.56)$, self-regulation ( $<<0.011, t=6.37)$, self-restraint $(p<0.035, t=4.29)$ and emotional self-organization ( $p$ $<0.042, p=0.222)$ predicted coronavirus anxiety, except self-motivation $(p<0.05, p=0.894)$.

Conclusions: Given that most subscales of executive function predict anxiety tied to critical situations such as the prevalence of coronavirus, it seems that greater attentions should be allocated to the fostering and development of children's executive functions by teaching such skills via playing.

\section{Background}

Coronavirus represents a large family of viruses that can cause respiratory infections, ranging from common colds to more severe respiratory illnesses such as MERS or SARS. The novel virus of this family has been called COVID-19, which broke out in Wuhan, China in December 2019. This virus may manifest mild to severe symptoms, including symptoms of infection such as fever, cough, and gasping. According to official statistics released by WHO, as of April 19, 2020, 237,987 cases of coronavirus have been identified worldwide, of which 16,3904 have died and 613,367 have recovered. This huge number of the infected and the deceased places a lot of pressure on government officials, doctors, nurses, and the general public. This epidemic not only poses a threat to physical health but also to the mental health of people (1). Accordingly, it is expected that the rising number of the infected and the deceased, the extension of lockdown and social distancing and the shutdown of schools and universities will wield influence on the mental health of children, adolescents and the youths. The effect of this epidemic on psychological indicators of the general population, patients, medical staff and adults has been the subject of growing scholarly attention (1). Huang and Zhao (2020) reported that during the outbreak of the COVID-19, anxiety and depression spiked in people under the age of 35 in China. These disorders are positively correlated with age and the degree of exposure to disease news (2), but scant attention has been paid to children anxiety during Coronavirus outbreak. Children seem to be especially vulnerable to anxiety, as most families are in home quarantine and constantly listen and discuss coronavirus statistics, which can create a stressful situation for children (3).Recurrent negative thoughts are a source of anxiety for children, which can exert deleterious effects on children in the 
long run. Anxiety has been shown to be linked to developmental, psychosocial, and psychological impairments. For example, anxiety has a detrimental effect on children's performance at school (4) and is the biggest risk factor for the development of other mental disorders such as depression (5). In addition, anxiety in childhood predicts psychological trauma in adolescence and youth (6). Therefore, it is important to identify factors that play a role in controlling childhood anxiety, both in terms of prevention and treatment.

It seems that the days of home quarantine and the outbreak of the COVID-19 have all the hallmarks of stressful situations, including preparation for stressful events, understanding the situation, uncertainty about the outcome, and coping with the stressor and its consequences (4). In general, anxiety can be assigned to three categories: trait anxiety, state anxiety, and situation-specific anxiety. Trait anxiety is defined as an enduring characteristic of a person. State anxiety denotes concerns about encountering a certain situation, and situation-specific anxiety describes the sense of fear and terror that one feels in a stressful situation (7). In this study, the anxiety induced by the outbreak of COVID-19 in children has been considered as situationspecific anxiety as it bears the hallmarks of a stressful situation, such as perceived fear of the virus, preparation for the stressful event, uncertainty about outcomes, coping strategies and its consequences (7). This type of stress may be symptomatic of physical and psychological distress in children. Meanwhile, there are huge individual differences between children in terms of the severity of stress they endure and the way they tackle these conditions. Therefore, by identifying the underlying factors of such individual differences we can strengthen them to better control the level of anxiety in future events so that children will experience less situation-specific anxiety in the event of similar crises in the future.

One of the factors that influence the level of situation-specific anxiety is executive function (8). Executive function is considered as a multi-dimensional goal-oriented system that regulates cognitive and behavioral processes of individuals to achieve desired goals (9). Cognitive aspects of executive function assessed by psychological tests include inhibition, perceptual motor speed, sustained attention, preservation, planning, reaction time, and working memory (10). So far, the bulk of studies have demonstrated the relation between cognitive aspects of executive function and anxiety (11). In this context, many studies have explored the relationship between poor working memory and elevated anxiety (12). However, Snyder et al. (2014) showed that cognitive impairment of executive functions like inhibition, working memory, attention switching, along with planning are the underlying causes of anxiety in children (13).

On the other hand, there are researchers who define executive functions as the cross-sectional organization of behaviors to attain future goals (14). It is unclear how psychology tests of executive functions, which are administered in clinics for only 5 to $30 \mathrm{~min}$ to assess executive functions, can endorse this aspect of executive function definition. These tests are usually conducted over a short period of time, as opposed to the enormous amount of time that individuals must dedicate to organizing and sustaining their activities for hours, days, or weeks to achieve their desired goals. Compared to tests that measure performance at the clinic, evaluating executive performance in the daily life, which measures behavior over a longer period of time, can probably be considered as an important indicator of organizing behaviors over a certain period of time and problem solving to achieve a specific goal. In other words, executive function is defined as a number of self-regulation skills such as emotional self-regulation, self-organization / problem-solving, self- 
restraint, self-motivation, and self-management to attain predefined goals (15). The following elaborates on the association between each of these related skills and anxiety.

Self-regulation is defined as the ability to suppress dominant impulses to moderate thoughts, behaviors, and emotions (16). Emotional self-regulation, which is based on the concept proposed by GROSS and THOMPSON 2007, comprises situation selection, situation modification, attentional deployment, cognitive change, and response modulation. It is likely that poor self-regulatory strategies will direct one's emotions toward other strategies that are not effective, which will ultimately lead to elevated levels of anxiety $(17,18)$. The results of a meta-analysis suggested that high levels of self-regulation are associated with lower levels of anxiety in children (16). Another study reported that children with less emotional self-regulation are more likely to experience anxiety and depression than other children (19). Barkelyanf Morphy (2011) showed that self-regulation was linked to anxiety (14).

Self-organization or problem-solving is a high-order cognitive ability that helps an individual deal with life's challenges (20). Based on the Bransford and Stein's (1984) model of problem solving, the steps of a problem are as follows. The Input phase in which a problem appears and attempts are made to figure out the problem. The Dealing phase where different alternatives are generated and evaluated and finally the best solution is selected. The Output phase involves planning for and executing the solution. Finally, there is the Re-assessment phase in which the solution is tested and necessary modifications are made (21). It has been shown that impaired self-organization / problem-solving may lead to self-oriented rumination, which will eventually aggravate anxiety in individuals (20). The negative problem orientation and rational problem solving are assumed to be the sources of trait anxiety and depression (22). Gail, Thomas, and Dzurita 1998 revealed that disability in solving social problems is associated with state anxiety in the elderly (23). Studies have shown that people with poor problem-solving abilities experience higher levels of anxiety (22). Also, Barkely and Morphy 2011 suggested that there is a relationship between self-organization and anxiety.

Self-restraint is conceptualized as the ability to quickly suppress self-directed tendencies to promote one's long-term goals (24). According to Weiberger, self-restraint includes intra-personal (impulse control), interpersonal (anger suppression and caring for others) and communal (responsibility) factors (25). People who are more socially compatible exhibit better self-restraint because they engage in self-management practices to present a positive impression to people and are not overly inexorable or enlightened (25-27). Poor self-restraint has been depicted to increase the level of state anxiety in people (24).

Self-motivation is defined as a stimulus that arises from one's inner tendency to fulfill one's needs (7). Chean and Gao (2014) argue that children experience anxiety when their self-motivation is impaired. Therefore, there is an inverse relationship between self-motivation and anxiety in children. On the other hand, Chen, Huang and Shang (2014) have exhibited the relationship between self-motivation and mental health in the elderly (28). Also, Barkely and Morphy (2011) demonstrated the association between self-motivation and anxiety (14).

Self-management describes the optimal use of available time, which reflects planning, goal setting, prioritization of goals and proper and effective execution of activities $(29,30)$. Self-management is a factor that plays a key role in anxiety. As a result of improper time management, a person would not have sufficient 
time to perform tasks such as social activities. This in turn dwindles the person's self-satisfaction and amplifies anxiety state (29). Kaya et al. (2012) suggested that students' time management skills are undercut when they are stressed (30). Ghiasvandi et al. also reported that nurses with poor self-management suffer from more anxiety (29). Barkely and Morph (2011) illustrated that that self-management is correlated with anxiety (14).

In the literature, the relationship between executive function skills and state or trait anxiety has been studied. However, to the best of authors' knowledge, no study has examined the relationship between anxiety level under a stressful global situation, such as the prevalence of a deadly disease, and executive function skills. A few studies have explored situation-specific anxiety in simulated environments. For example, exams or learning a second language test have been proposed as stressful situations. Certainly, the level of anxiety perceived by an individual during these conditions is not comparable to the real cause of a deadly epidemic. For example, a 1993 study by Zeidner found that state anxiety in students spiked significantly during the final semester exams (4). Therefore, under real-life conditions, one can accurately investigate the role of selfregulation skills in the level of disease anxiety. However, to the best of our knowledge, there is no study on the relationship between self-related skills of executive functions and situation specific anxiety. Therefore, the primary objective of this study is to investigate the association between self-related skills of executive functions and COVID-induced anxiety. The secondary goal is to predict COVID-induced anxiety based on the subscales of executive functions.

\section{Methods}

\section{Participants}

The study included 300 healthy children, including 103 girls (34.33\%) and 197 boys (65.66\%) between the ages of 8 and $12(M=10.7$; SD: 1.95). Participants were selected through giving out flyers at schools and universities. Initial assessments consisted of structured clinical interviews with children and their parents. The exclusion criteria were: 1- mental disorders such as autism, hyperactivity, anxiety, depression, developmental coordination disorder in the past or at the present; 2- use of psychotropic drugs; 3- IQ less than 85 ; 4 - Being above or below the study age range, and 5- physical disorders.

\section{Material}

1- Coronavirus Anxiety Scale: This Persian form of Coronavirus Anxiety Scale has been developed and validated to measure anxiety induced by the outbreak of Coronavirus. The final version of this scale contains 18 items and 2 variables. Items 1 to 9 measure psychological symptoms and items 10 to 18 measure physical symptoms. The instrument is scored on a 4-point Likert scale (never $=0$, sometimes $=1$, often $=2$, and always $=3$ ), so the highest and lowest scores will be in the range of 0 and 54 . High scores in this scale indicate a greater level of anxiety in individuals. The reliability of this tool was assessed using Cronbach's alpha method for the first (-0.879), and second (-0.861) variables and for the whole scale (-0.99). After selecting the questionnaire, the confirmatory factor analysis was used to validate Coronavirus anxiety scale before the study. The results of model fitness indicators (NNFI =0.98, NNFI = 0.99, CFI = 0.97, IFI: 0.99, GFI = 
0.99, $\mathrm{AGFI}=0.98, \mathrm{RMSEA}=0.052, \mathrm{df}=125, \mathrm{X} 2=36 / 227, \mathrm{X} 2 / \mathrm{df}=1.81$ ) suggested that the bivariate model of Coronavirus Anxiety was fit. Hence, it can be concluded that the factor structure of Coronavirus Anxiety Scale is confirmed and it is valid for the research sample. In addition, Cronbach's alpha test was used to verify the reliability of the instrument. The results illustrate the acceptable reliability of this scale in the present study.

2 - Barkley Deficits in Executive Functioning Scale (BDEFS): This scale was designed by Barkley (2012) to represent executive functions in non-clinical and clinical populations, especially children and adolescents. This 70-item scale is scored on a 4-point Likert scale ranging from never to always. It also contains 5 subscales that measure executive functions of self-management (items 1-13), emotional self-regulation (items 14-27), self-restraint (item 28-40), self-motivation (item 41-54) and self-organization / problem solving (items 55 to 70). Seven scores are extracted: five are subscales, one is the total score and another score is calculated from 11 items of this scale, which are considered as the list of executive functions. Scores between 70 and 140 denote deficit in executive functions, scores between 140 and 175 reveal moderate deficit in executive functions, and scores of above 175 suggest severe deficit in executive functions (31). This scale has been translated into Persian and its validity and reliability have been corroborated in many studies.

\section{Research Design}

The present study is a correlational research. In November and December 2019, the news about the outbreak of Coronavirus in Wuhan, China, was first heard and soon this disease spread to other countries around the world. Assuming that COVID-19 would hit our country, we set out to conduct a research to study children that were better able to cope with the anxious conditions of this disease during the quarantine and the spread of the epidemic in Iran. To this end, a study was designed to investigate the link between one of the underlying factors in the control of anxiety, namely executive functions skills, and the anxiety induced by this disease in children. To do so, using flyer advertisements at schools, universities, and the city, parents of children aged 8-12 years old in Mashhad were invited to participate in the study for assessment of their children's skills by contacting the first author of this study. A briefing session was arranged for participants, and the parents were asked to refer to the clinic at the designated time and day. During the orientation session, the goals of the study were explained to the participants and the parents signed an informed consent form for participation in the study. Subjects were told that they had the right to withdraw from the study at any time. Finally, 400 participants were recruited for the study. Then, children's descriptive information as well as the contact number, email, WhatsApp and Telegram ID of parents were registered in the clinic's database. In the next step, a psychologist examined the children's mental health, and the children's physical health was assessed by a pediatrician. Of all participants, 100 were excluded due to mental or physical disorders or parents' unwillingness to participate in the study. Parents also filled out the Barkley Deficits in Executive Functioning Scale. In early December, when Coronavirus broke out ..., schools were shut down and home quarantine initiated. The second phase of our study was conducted two months after home quarantine in February. We contacted the parents via the Internet and asked them to fill out Coronavirus anxiety questionnaire for their child. At this stage of the study, all parents completed the questionnaire and there was no dropout. Finally, the information obtained from 300 participants was examined. This study was approved 
by ethics committee of the biological research center of Ferdowsi University of Mashhad, Iran (Approval Number IR.UM.REC.1399.014). The study was conducted in compliance with the principles of the Declaration of Helsinki.

\section{Statistical Analysis}

Before data analysis, the normality of data distribution was examined. The results manifested that all data was normally distributed. Pearson correlation method was recruited to investigate the relationship between executive functions and anxiety scores. A significance level of 0.05 was considered for this test. Then, a model was developed to investigate the relationship between executive function components and anxiety. For the model, the assumptions regarding the linearity of variables and the independence of errors were examined. The results showed that the tolerance index for all predictor variables was less than 0.95 , the variance inflation factor (VIF) was less than 1.85, and the Durbin-Watson index, which is used to test the assumption of error independence, was 2.14. When the tolerance index is greater than 0.10 , the VIF is less than ten $(10>$ VIF), and the Durbin-Watson value is less than four (4 > Durbin-Watson), it can be argued that regression assumptions have not been violated. Therefore, in light of the obtained indicators, it can be concluded that test conditions have been properly observed. Accordingly, the structural equation method was used to fit the model. A significant level of less than 0.01 and 0.001 was considered for the test. Multiple regression tests were also performed to assess the power of executive function factors in predicting the prevalence of COVID-19 anxiety. A significance level of less than 0.05 was set for this test. Data was analyzed using SPSS 19.5 software.

\section{Results}

\section{Descriptive features of participants}

In this study, data was collected from 300 participants in the age range of 8 to 12 years (average age of 10 years and 7 months). The descriptive indicators related to research variables, i.e. executive functions and anxiety for the research participants are shown in Table 1.

Table 1

Descriptive characteristics of research variable

\begin{tabular}{|lcccl|}
\hline Variables & Mean & SD & K-sz & p. value \\
\hline Self-management & 30.14 & 3.38 & 1.62 & 0.14 \\
\hline Self-organization & 36.16 & 4.12 & 1.48 & 0.21 \\
\hline Self-restraint & 32.58 & 3.52 & 1.38 & 0.32 \\
\hline Self-motivation & 37.70 & 4.75 & 1.55 & 0.18 \\
Self-regulation & 45.46 & 6.83 & 1.42 & 0.24 \\
\hline Total score of self-relate EF & 182.45 & 16.67 & 1.88 & 0.07 \\
\hline Anxiety & 32.44 & 6.82 & 1.85 & 0.12 \\
\hline
\end{tabular}


As shown in Table 1, the mean and standard deviation for the scale of executive functions and the coronavirus anxiety scale were (16.26), 182.45 and 32.44 (6.82), respectively. Also, the Kolmogorov-Smirnov statistic was not significant for the total score of executive functions, Coronavirus anxiety scales $(p>0.05)$. Hence, the executive functions and Coronavirus anxiety scales had normal distribution.

\section{Relationship Between Components Of Executive Functions And Anxiety}

The correlation matrix of executive functions and anxiety scales is shown in Table 2.

Table 2

Pearson correlation coefficient of research variables

\begin{tabular}{|c|c|c|c|c|c|c|c|}
\hline & $\begin{array}{l}\text { Self- } \\
\text { management }\end{array}$ & $\begin{array}{l}\text { Self- } \\
\text { organization }\end{array}$ & $\begin{array}{l}\text { Self- } \\
\text { restraint }\end{array}$ & $\begin{array}{l}\text { Self- } \\
\text { motivation }\end{array}$ & $\begin{array}{l}\text { Self- } \\
\text { regulation }\end{array}$ & $\begin{array}{l}\text { Total } \\
\text { score }\end{array}$ & Anxiety \\
\hline $\begin{array}{l}\text { Self- } \\
\text { management }\end{array}$ & 1 & & & & & & \\
\hline $\begin{array}{l}\text { Self- } \\
\text { organization }\end{array}$ & 0.36 & 1 & & & & & \\
\hline $\begin{array}{l}\text { Self- } \\
\text { restraint }\end{array}$ & 0.28 & 0.31 & 1 & & & & \\
\hline $\begin{array}{l}\text { Self- } \\
\text { motivation }\end{array}$ & 0.33 & 0.25 & 0.27 & 1 & & & \\
\hline $\begin{array}{l}\text { Self- } \\
\text { regulation }\end{array}$ & 0.37 & 0.23 & 0.24 & 0.29 & 1 & & \\
\hline Total score & 0.53 & 0.55 & 0.49 & 0.46 & 0.51 & 1 & \\
\hline Anxiety & -0.44 & -0.47 & -0.49 & -0.12 & -0.48 & -0.53 & 1 \\
\hline
\end{tabular}

As displayed in the table above, the overall score of executive functions and its subscales except selfmotivation are negatively correlated with coronavirus anxiety at a level of $p=0.05$.

\section{Structural Equation Modeling}

Structural equation modeling was used to corroborate the relationship between executive skills and coronavirus anxiety. The total score of the executive function (consisting of self-management, selforganization, self-restraint, self-motivation, self-regulation), as the criterion variable and the total score of coronavirus anxiety as the predictor variable, were entered in the model. The model path coefficients are especially important in this method, because if the model path coefficient is without a predictive value, then regression method will be meaningless. Our model, had desirable fitness, so that Comparative Fit Index (CFI) and the Tucker-Lewis index should be equal or greater than 0.95. In our study, these indices were 0.98 and 0.96 , respectively. 
Standardized Root Mean Square Residual (SRMR) should be less than 0.08 , and the Root Mean Square Error of Approximation (RMSEA) should be less than 0.06 . In our study, these indices were 0.77 and 0.05 , respectively. Figure 1 shows the fitted pattern of predicting coronavirus anxiety by executive functions.

\section{Note}

The numbers inside the parentheses indicate the standard path coefficient and the numbers outside the parentheses exhibit the non-standard path coefficient. S1: self-management, S2: self-organization, S3: selfrestraint, S4: self-motivation, S5: self-regulation, F1: mental factors, F2: physical factors.

\section{Predicting Coronavirus Anxiety As A Component Of Executive Functions}

In the regression model, the association between five components of executive function demonstrated the significant role of coronavirus anxiety variance $F(4.295)=8.55, p<.01,0.28=2 R$. However, only four components of executive function significantly predicted coronavirus anxiety. Self-management $(\beta=.42, t=$ $-5.56, p=.015)$, self-regulation $(\beta=-.25, t=-3.22, p=.04)$, self-restraint $(\beta=-.37, t=-4.29, p=.035)$, and selforganization / problem solving $(\beta=-.45, t=-6.37, p=.011)$ were significant predictors of coronavirus anxiety. These results suggest that participants who had a poor performance in these components were more likely to suffer from anxiety induced by crises such as coronavirus outbreak.

\section{Discussion}

The main goal of this study was to investigate whether self-related skills of executive functions was associated with situation-specific anxiety induced by the outbreak of the COVID-19 in children. According to the findings, there is a $53 \%$ negative correlation between the total score of executive function and coronavirus anxiety, and given that this effect is negative, it can be contended that a higher level of selfrelated skills of executive functions in children will reduce their anxiety in the face of stressful situation like coronavirus outbreak.

Our results suggested that coronavirus anxiety was negatively and significantly associated with the emotional self-regulation, elf-organization / problem-solving, self-restraint, self-motivation, and selfmanagement. In other words, these results demonstrated that impairment in these components of executive function was associated with augmented anxiety of children during the outbreak of COVID- 19.

The strength of these skills associated with executive functions indicates that individuals make use of their skills to achieve their desired goals, which allows them to manage life challenges and stay on track for their goals. The results of our study, consistent with Ensenberge et al., exhibited a negative relationship between emotional self-regulation and anxiety in children. In the context of the global epidemic crisis, it appears that children able to moderate negative thoughts, understand the situation and respond appropriately will endure lower anxiety. Although the development of self-regulatory skills is a process linked to cognitive development (executive functions) and genetics (32), the role of the environment in the development of this skill should not be overlooked. Therefore, as an environmental factor, family plays a key role in developing children's selfregulatory skills. Researchers reported that emotional self-regulation of children in the family takes place at three levels including social response to the child's feelings, social expression of feelings in the family or about the child, and talking about emotions (33). Research has shown that parents sensitive to and 
responsible for their children's emotions will improve the growth of emotional self-regulation in their children (34-36). Moreover, parental love and positivity are other factors that contribute to emotional self-regulation in children (37). The second level is parental response to the expression of children's feelings, especially negative ones. As a result of this reaction, children experience important and valuable information about the expression of unpleasant feelings (17). The support of parents and the channeling of emotions can help children alleviate negative emotions, allowing them to directly cope with their emotions. The third level is related to the importance of discussing feelings and emotions within the family. When parents talk to their children about emotions, they are basically teaching the meaning of a wide array of emotions to their child under diverse circumstances, which is indirectly related to the development of emotional regulation skills in children. During the emotional self-regulation of children, they must be capable of self-organization or addressing the problem at hand.

The self-organization / problem solving skill in our study was negatively and significantly associated with anxiety levels in children. This means that a higher level of self-organization / problem solving skills in children is associated with lower perception of anxiety. This aligned with the findings of Barkely and Morphy 2011. Problem-solving ability is considered as a mediator between the stressful life events and amplified stress in an individual (23). People with advanced problem-solving skills are less likely to experience anxiety in the face of stressful events in their life. Self-organization / problem-solving skills have been shown to be directly linked to competence, productivity, and positivity (21). It has been suggested that in order to solve a problem, we need to first define the problem or issue, identify the solutions, make a decision, and finally execute that decision (38). It seems that since COVID-19 has triggered a new deadly disease, posing a tremendous challenge to all families, it is highly important to implement these four activities to relieve anxiety in children. For all predicaments and problems that a child may face during his lifetime, this method can be utilized to teach problem-solving skills, so that the child eventually develops a problem-solving style that could be utilized to boost her/his life satisfaction. In some cases, it is observed that people need selfrestraint skills to deal with problems in order to suppress personal desires and wishes that are not conducive to the resolution of the problem.

An individual with poor self-restraint is unable to suppress her/his desires. Hence, observing the deterioration of a problem intensifies stress. The results of our study manifested that self-restraint has an inverse and significant relationship with anxiety, which aligns with the study of Farell and Sullivan (2000), according to which poor self-restraint raises the level of state anxiety in the individual (24). According to Weinbergers (1998), self-restraint is a developmental achievement and an indicator of emotional maturity (39). Although high self-restraint exhibits the ability to refrain from impulsive behaviors, it is also associated with a desire to align yourself with the majority of people in the society and a controlled style of coping (39). It seems that under stressful situations, children should first be informed of the intra-personal factors of this problem. They should be then assisted to manage their anger and show regard for the health of other people in society, while their sense of social responsibility is stimulated. This can be justified within the framework of Weinberge. When a child figures out the reasons for her/his self-restraint, which might be in line with her long-term goals in life, she may be able to tolerate a lower-level anxiety. At this time, when the child has to give up her desires, self- management comes to fore in order to avoid squandering time and to start educational processes. 
Our study revealed that time management had an inverse relationship with anxiety. In other words, children with positive self-management experiences endure less anxiety. This is in line with a 2008 study by Ghiasvandi et al. according to which stronger self-management in nurses reduced their anxiety (29). For the purpose of time management, planning, goal setting, prioritization, and execution are required. People with great time management do not focus on a particular subject for a long time, but divide their time among different activities such as work, personal life, and performance of favorite activities (30). In this regard, planning to attain goals gained urgency. We need to plan the time available so that we can reach our goals in the shortest time possible. Lack of efficient planning in children's lives may interfere with their academic success. Therefore, it seems that during home quarantine, especial planning is required for spending time so that children can engage in educational activities along with other activities at home. The stress inherent in learning educational materials, in addition to the risk of disease, can build up anxiety in children.

On the other hand, the results of our study revealed that there was no significant relationship between selfmotivation and coronavirus anxiety. Barkely and Morphy (2011) demonstrated a negative relationship between self-motivation and anxiety in adults with attention deficit hyperactivity disorder. Chen, Huang and Shang also reported a negative and significant association between self-motivation and anxiety in the elderly. As mentioned earlier, the statistical population of these studies consisted of adults, while our statistical population comprised children, and we did not find a significant relationship between selfmotivation and anxiety. Self-motivation has a positive and significant relationship with mental health. Selfmotivation is at work when the goal is sufficiently captivating, important and compatible with the goals of that person (40). It appears that children are not able to set proper goals due to their undeveloped cognitive abilities, or organize their activities to achieve that goal. Given the lack of purpose and of behavioral regulation strategies to achieve their goals, they may grow anxious. On the other hand, children do not seem to be able to internally reinforce their positive behaviors and use positive self-talk techniques to guide their behavior toward the selected goals.

The second goal of the study was to determine the extent to which subscales of executive function were able to predict the anxiety associated with the prevalence of the COVID-19. Our results exhibited that skills related to self-executive functions were generally able to explain $28 \%$ coronavirus stress. Regression test revealed that the self-management component, emotional self-regulation, self-restraint, and self-organization / problem solving can predict coronavirus anxiety, but the component of self-motivation is not able to predict coronavirus anxiety. Children reported to have poor self-management, emotional self-regulation, self-restraint, and self-organization / problem-solving skills were more likely to endure anxiety during the outbreak of coronavirus. Children grown up in families that have taught them how to adjust their emotions in the face of life's challenges, and have supportive parents are more capable of controlling their negative thoughts during the outbreak of the coronavirus, which in turn diminishes their anxiety.

On the other hand, children who are able to curb desires and aspirations that do not contribute to the containment of the disease under these critical situations, and are aware of their individual and social responsibility, experience less anxiety. Also, children with greater self-organization/problem solving ability can understand the importance of current strategies of tackling the crisis including staying home, not going to school, and not playing with their friends, for these measures are vital to deal with this crisis. By being 
aware of such measures, they will become less anxious. In the end, children with more efficient time management skills will be more successful in planning their time at home quarantine and attaining goals they have set for themselves, which in turn relieve their anxiety.

Given that most components of executive function are able to predict anxiety tied to critical situations such as the prevalence of coronavirus, it seems that families should utilize above-mentioned methods to reinforce each component of their executive functions and to pay greater attentions to the growth and development of children's executive functions. Since anxiety has been shown to be the underlying cause of other mental disorders in later life. In general, skills related to executive functions describe influencing and controlling the external environment while controlling one's own skills at the same time. Lack of coordination in these skills prevents in individuals from reacting properly to anxiety-inducing situations and consequently they may endure mounting anxiety.

\section{Limitation and consideration}

Overall, these results suggest that skills related to executive functions are negatively associated with coronavirus anxiety. The present study provides evidence that coronavirus anxiety may be linked to underlying reasons such as impaired executive skills. One of the limitations of this study is that due to home quarantine and the lack of access to children, we were not able to implement psychological tests to evaluate executive functions. However, it has been suggested that laboratory tests for evaluation of executive function are often unable to identify disorders in high-order executive functions (41). The use of laboratory tests in future research may illustrate the relationship between self-reported executive functions, laboratory tests of executive function, and anxiety levels. In addition, it can offer evidence that repudiate or confirm the use of the self-report executive function against laboratory tests. Finally, since this is the first study to directly evaluate the relationship between executive skills and anxiety induced by epidemic conditions of coronavirus prevalence, it is inherently exploratory in nature. Although the results of this study reveal that there is a negative and significant relationship between executive function skills and anxiety, it is still too early to interpret the strength and direction of this relationship and further studies are needed.

\section{Conclusion}

Despite the aforesaid limitations, this study also has some strengths. First of all, we explored children's anxiety under coronavirus crisis, while other studies have mainly focused on adults or medical staff. The present study examines this vulnerable group of people that play a crucial role in the future progress of the country and their mental health is a key factor in obtaining these goals. Executive functions are one of the underlying components of mental health, the foundation of which is built in childhood, when the skills related to oneself are learned. Therefore, childhood is of paramount importance in terms of laying the basis of mental health. Finally, families and teaching staff are advised to help children express their emotion and feelings of security and to support them express emotions, especially negative ones (emotional selfregulation). Further, they can help children find a suitable problem-solving style (self-organization/ solving problems), assume individual and interpersonal responsibility (self-restraint), and manage their time more efficiently (self-management). It is because these behaviors allow children to build and strengthen their self- 
skills. As a result, children can apply these executive skills to attain their designated goals in life. It is the highest level of cognition that a person can achieve during his or her developmental life.

\section{Declarations}

\section{Consent for publication}

This article is original, has not already been published in a journal, and is not currently under consideration by another journal. All authors of the manuscript have read and agreed to its content and are accountable for all aspects of the accuracy and integrity of the manuscript in accordance with ICMJE criteria.

\section{Availability of data and material}

We would be happy to share our materials on request.

\section{Funding}

Not applicable

\section{Competing interest}

The authors declare that they have no competing interests.

\section{Authors' contribution}

Sakineh Soltani Kouhbanani and Maryam Bordbar are involved in the conception and design of the study. Seyedeh Manizheh Arabi did the statistical analysis. Somayeh Zarenezhad wrote the initial draft of manuscript. Sakineh Soltani Kouhbanani was project leaders. All authors read and approved the final manuscript.

\section{Author details}

Sakineh Soltani Kouhbanani, Assistant professor, Department of Educational Sciences, Educational sciences and Psychology Faculty, Ferdowsi University of Mashhad, Mashhad, Iran

Maryam Bordbar, Assistant professor, Department of Educational and Counselling Psychology, Educational sciences and Psychology Faculty, Ferdowsi University of Mashhad, Mashhad, Iran. mbordbar@um.ac.ir

Somayeh Zarenezhad. M.A of psychology, Department of Educational Sciences, Educational sciences and Psychology Faculty, Ferdowsi University of Mashhad, Mashhad, Iran. zarenezhadsomaye@gmail.com

Seyedeh Manizheh Arabi, Ph.D. of Motor Development, Department of Motor Behavior, Faculty of Sport Sciences, Ferdowsi University of Mashhad. Mashhad, Iran. Ma.arabi@mail.um.ac.ir

\section{Acknowledgements}

We are grateful to the families who took part in our research. 


\section{Ethics approval and consent to participate}

Ethics approval to conduct this trial was obtained from Ferdowsi University of Mashhad Human Research Committee (Approval Number IR.UM.REC.1399.014) and registered in Iran National Committee for Ethics in Biomedical Research.

\section{References}

1. Cao W, Fang Z, Hou G, Han M, Xu X, Dong J, et al. The psychological impact of the COVID-19 epidemic on college students in China. Psychiatry research. 2020:112934.

2. Huang Y, Zhao N. Generalized anxiety disorder, depressive symptoms and sleep quality during COVID-19 epidemic in China: a web-based cross-sectional survey. medRxiv. 2020.

3. Li Q, Guan X, Wu P, Wang X, Zhou L, Tong Y, et al. Early transmission dynamics in Wuhan, China, of novel coronavirus-infected pneumonia. New England Journal of Medicine. 2020.

4. Zeidner M. Personal and contextual determinants of coping and anxiety in an evaluative situation: A prospective study. Personality Individual differences. 1994;16(6):899-918.

5. Wittchen HU, Fehm L. Epidemiology and natural course of social fears and social phobia. Acta Psychiatr Scand. 2003;108:4-18.

6. Copeland WE, Shanahan L, Costello EJ, Angold A. Childhood and adolescent psychiatric disorders as predictors of young adult disorders. Archives of general psychiatry. 2009;66(7);764 - 72..

7. Shirvan ME, Khajavy GH, Nazifi M, Taherian T. Longitudinal examination of adult students' self-efficacy and anxiety in the course of general English and their prediction by ideal self-motivation: Latent growth curve modeling. New Horizons in Adult Education Human Resource Development. 2018;30(4):23-41.

8. Bishop SJ. Neurocognitive mechanisms of anxiety: an integrative account. Trends Cogn Sci. 2007;11(7):307-16.

9. Kruglanski AW, Higgins ET. Social psychology: Handbook of basic principles: Guilford Publications; 2013.

10. Affrunti NW, Woodruff-Borden J. The associations of executive function and temperament in a model of risk for childhood anxiety. J Child Fam Stud. 2015;24(3):715-24.

11. Silton RL, Heller W, Engels AS, Towers DN, Spielberg JM, Edgar JC, et al. Depression and anxious apprehension distinguish frontocingulate cortical activity during top-down attentional control. J Abnorm Psychol. 2011;120(2):272.

12. Ursache A, Raver CC. Trait and state anxiety: Relations to executive functioning in an at-risk sample. Cognition emotion. 2014;28(5):845-55.

13. Sharp PB, Miller GA, Heller W. Transdiagnostic dimensions of anxiety: neural mechanisms, executive functions, and new directions. Int J Psychophysiol. 2015;98(2):365-77.

14. Barkley RA, Murphy KR. The nature of executive function (EF) deficits in daily life activities in adults with $A D H D$ and their relationship to performance on EF tests. Journal of Psychopathology Behavioral Assessment. 2011;33(2):137-58. 
15. Franklin P, Tsujimoto KC, Lewis ME, Tekok-Kilic A, Frijters JC. Sex differences in self-regulatory executive functions are amplified by trait anxiety: The case of students at risk for academic failure. Personality Individ Differ. 2018;129:131-7.

16. Robson DA, Allen MS, Howard SJ. Self-regulation in childhood as a predictor of future outcomes: A meta-analytic review. Psychological bulletin. 2020.

17. Eisenberg N, Spinrad TL, Eggum ND. Emotion-related self-regulation and its relation to children's maladjustment. Ann Rev Clin Psychol. 2010;6:495-525.

18. Snyder HR, Kaiser RH, Warren SL, Heller W. Obsessive-compulsive disorder is associated with broad impairments in executive function: A meta-analysis. Clinical Psychological Science. 2015;3(2):301-30.

19. Eisenberg N, Morris AS. Children's emotion-related regulation. 2002.

20. Sternheim L, Danner U, van Elburg A, Harrison A. Do anxiety, depression, and intolerance of uncertainty contribute to social problem solving in adult women with anorexia nervosa? Brain and Behavior. 2020.

21. Khan MJ, Younas T, Ashraf S. Problem solving styles as predictor of life satisfaction among university students. Pakistan Journal of Psychological Research. 2016;31(1).

22. Balck F, Zschieschang A, Zimmermann A, Ordemann R. A randomized controlled trial of problem-solving training (PST) for hematopoietic stem cell transplant (HSCT) patients: Effects on anxiety, depression, distress, coping and pain. J Psychosoc Oncol. 2019;37(5):541-56.

23. Maydeu-Olivares A. Soeial Problem Solving as a Mediator of Stress-Related Depression and Anxiety in Middle-Aged and Elderly Community Residents\&\#8217.

24. Farrell AD, Sullivan TN. Structure of the Weinberger Adjustment Inventory Self-Restraint scale and its relation to problem behaviors in adolescence. Psychol Assess. 2000;12(4):394.

25. Weinberger DA, Schwartz GE. Distress and restraint as superordinate dimensions of self-reported adjustment: A typological perspective. Journal of personality. 1990;58(2):381-417.

26. Asendorpf JB, van Aken MA. Resilient, overcontrolled, and undercontroleed personality prototypes in childhood: Replicability, predictive power, and the trait-type issue. J Personal Soc Psychol. 1999;77(4):815.

27. Hart D, Hofmann V, Edelstein W, Keller M. The relation of childhood personality types to adolescent behavior and development: A longitudinal study of Icelandic children. Dev Psychol. 1997;33(2):195.

28. Chen C, Huang J, Shang H. Influence of Self Motivation on Mental Health of Elderly People. Med One. 2016;1(5).

29. Ghiasvand AM, Naderi M, Tafreshi MZ, Ahmadi F, Hosseini M. Relationship between time management skills and anxiety and academic motivation of nursing students in Tehran. Electronic physician. 2017;9(1):3678.

30. Kaya H, Kaya N, Palloş A, Küçük L. Assessing time-management skills in terms of age, gender, and anxiety levels: A study on nursing and midwifery students in Turkey. Nurse Educ Pract. 2012;12(5):2848.

31. Prevatt F, Osborn D, Coffman TP. Utility of the Barkley Deficits in Executive Functioning Scale (BDEFS) for career planning in college students with ADHD. Career Planning Adult Development Journal. 2015;31(4):69-79. 
32. Lemery-Chalfant K, Doelger L, Goldsmith HH. Genetic relations between effortful and attentional control and symptoms of psychopathology in middle childhood. Infant Child Development: An International Journal of Research Practice. 2008;17(4):365-85.

33. Eisenberg N, Cumberland A, Spinrad TL. Parental socialization of emotion. Psychological inquiry. 1998;9(4):241-73.

34. Li-Grining CP. Effortful control among low-income preschoolers in three cities: Stability, change, and individual differences. Dev Psychol. 2007;43(1):208.

35. Rodriguez ML, Ayduk O, Aber JL, Mischel W, Sethi A, Shoda Y. A contextual approach to the development of self-regulatory competencies: The role of maternal unresponsivity and toddlers' negative affect in stressful situations. Soc Dev. 2005;14(1):136-57.

36. Spinrad TL, Eisenberg N, Gaertner B, Popp T, Smith CL, Kupfer A, et al. Relations of maternal socialization and toddlers' effortful control to children's adjustment and social competence. Dev Psychol. 2007;43(5):1170.

37. Gaertner BM, Spinrad TL, Eisenberg N. Focused attention in toddlers: Measurement, stability, and relations to negative emotion and parenting. Infant Child Development: An International Journal of Research Practice. 2008;17(4):339-63.

38. Ahvan YR, Zainalipour H, Jamri M, Mahmoodi F. The correlation between Gardner's multiple intelligences and the problem-solving styles and their role in the academic performance achievement of high school students. European Online Journal of Natural Social Sciences. 2016;5(1):32.

39. Blagov PS, Singer JA. Four dimensions of self-defining memories (specificity, meaning, content, and affect) and their relationships to self-restraint, distress, and repressive defensiveness. Journal of personality. 2004;72(3):481-511.

40. Owen KB, Smith J, Lubans DR, Ng JY, Lonsdale C. Self-determined motivation and physical activity in children and adolescents: A systematic review and meta-analysis. Preventive medicine. 2014;67:270-9.

41. Barkley RA. Executive functions: What they are, how they work, and why they evolved: Guilford Press; 2012.

\section{Figures}




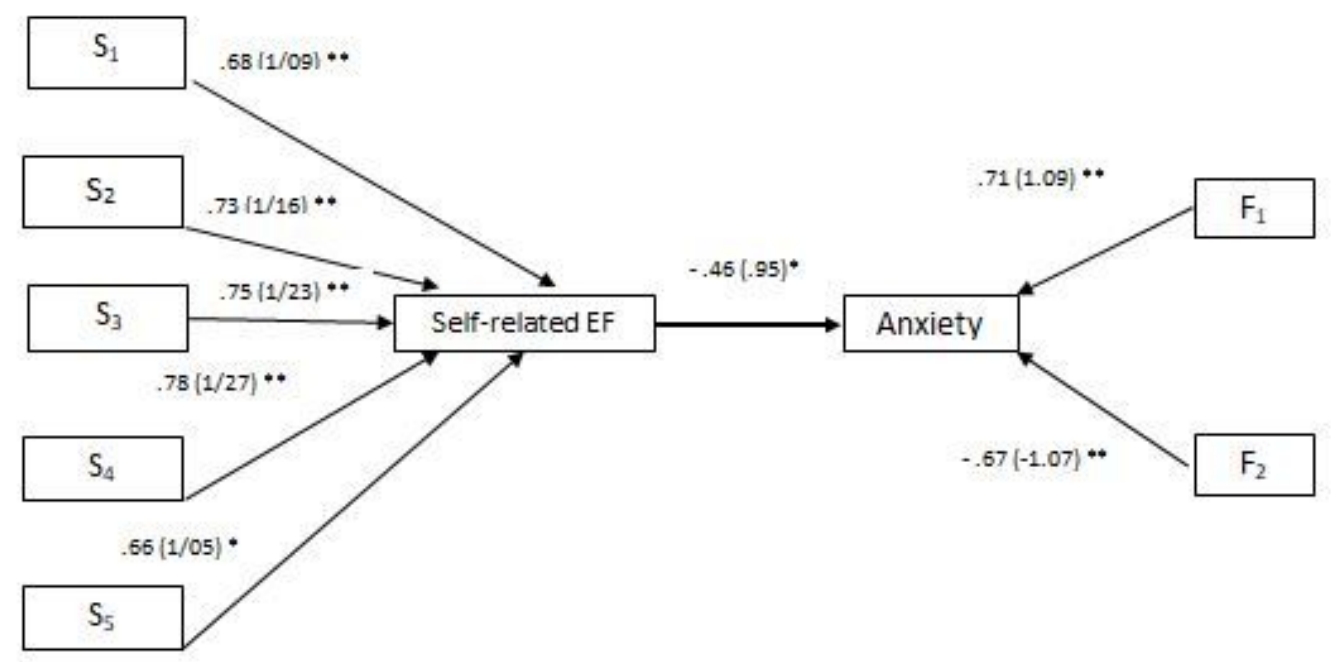

* $p<.01$

$* p<.001$

Figure 1

Path coefficient with respect to the relationship between executive function and Coronavirus anxiety. 